\title{
Proposed Specifiers for Conduct Disorder-Short Version (PSCD-SV): Psychometric Properties, Concurrent Correlates and Parenting Predictors
}

\author{
Laura López-Romero $^{1}$ (D) Olalla Cutrín ${ }^{1} \cdot$ Lorena Maneiro $^{1,2} \cdot$ Randall T. Salekin $^{3}$
}

Accepted: 8 February 2022

(c) The Author(s) 2022

\begin{abstract}
The present study aims to further examine the four-factor model of psychopathy in adolescence with a new alternate model for the assessment of psychopathic traits and conduct disorder (CD): The Proposed Specifiers for Conduct Disorder-Short version (PSCD-SV). Data were collected in a sample of 414 adolescents (49.2\% females) aged 12-15 at the first assessment who were then followed-up 2 years later. Results supported the usefulness of the PSCD-SV to assess the broader construct of psychopathy showing good psychometric properties, including adequate reliability and validity, while accounting for all its dimensions. In addition, the study showed close associations between psychopathic traits and adolescent behavioral, emotional and psychosocial maladjustment. Finally, the findings elucidated the PSCD's connection to parental support and psychological control, and reinforced the potential role of parenting practices as predictors that can act as mechanisms of change in the development of psychopathy. Overall, current findings shed light on conceptual and developmental models of psychopathy that may have implications for assessment, diagnostic classification, prevention, and intervention.
\end{abstract}

Keywords PSCD-SV $\cdot$ Psychopathic traits $\cdot$ Conduct disorder $\cdot$ Parenting practices $\cdot$ Adolescence

Psychopathy or psychopathic personality has been traditionally defined as constellation of co-occurring interpersonal (e.g., deceitfulness, grandiosity), affective (e.g., callousness, lack of remorse), and behavioral dimensions (e.g., impulsivity, irresponsibility), in addition to antisocial traits and behaviors [1]. Largely based on the work developed through the Psychopathy Checklist-Revised [2], factor analytical studies have explored different models and structures. Initially, a two-factor structure, including an interpersonalaffective dimension (Factor 1) and an impulsive-antisocial dimension (Factor 2) was revealed [3]. A three-factor model was later proposed by separating Factor 1 into two

Laura López-Romero

laura.lopez.romero@usc.es

1 Department of Clinical Psychology and Psychobiology, Facultad de Psicología, Universidade de Santiago de Compostela, Campus Sur, 15782 Santiago de Compostela, Spain

2 Institute of Education and Child Studies, Leiden University, Leiden, The Netherlands

3 Department of Psychology, The University of Alabama, Tuscaloosa, USA components (i.e., interpersonal and affective) and dropping antisocial items from Factor 2 to form a single lifestyle component [4]. Later, the traditional two-factor model of psychopathy was reformulated as a four-factor construct reincorporating antisocial behavior with interpersonal (facet 1) and affective (facet 2) domains comprising the traditional Factor 1, and lifestyle (facet 3) and antisocial behavior (facet 4) as separate domains of traditional Factor $2[1,2]$.

During the past two decades, research on psychopathic personality has also been extended downward in age, being studied in childhood and adolescence [5, 6]. In this regard, prior research has described child psychopathy as a multifaceted construct, including interpersonal [i.e., GrandioseManipulative (GM)], affective [i.e., Callous-Unemotional (CU)], and behavioral/lifestyle dimensions [i.e., Daring-Impulsive (DI)] that can be observable at an early age [7], are relatively stable across time [8], and show specific meaningful correlations with cognitive, emotional, personality and psychosocial variables [9]. In line with adult literature, two-, three-, and four-factor solutions were also statistically explored at early developmental stages, with most studies conducted with diverse samples of children and adolescents supporting a three-factor structure [7, 10-13], 
albeit some evidence for a four-factor structure has been also provided [12, 14, 15]. Even considering a three- or a fourfactor model when assessing psychopathic traits in young samples, all psychopathy dimensions have been shown to be associated with a large set of psychosocial and behavioral problems, including conduct problems, aggression, low prosocial behavior, antisocial behavior and offending [16].

Further support for considering the entire syndrome, as well as recognizing all its dimensions, has been recently provided. Different studies conducted in different samples of preschoolers, school-aged children and adolescents from several countries, found that the combination of high levels of all three psychopathy dimensions (i.e., interpersonal, affective, and behavioral/lifestyle) and conduct problems was most strongly related to child and youth behavioral and psychosocial maladjustment (e.g., conduct problems, aggression, ADHD) measured both concurrently and prospectively [17-22]. From these results, the authors conclude that the multidimensional model for child and adolescent psychopathy, in combination with concurrent conduct problems, seems to be more effective for predicting behavioral problems than considering only $\mathrm{CU}$ traits and, therefore, it may offer greater utility to researchers and clinicians for both prediction and specification of conduct disorder (CD) [16].

Although there seems to be enough support for considering psychopathy as a multidimensional construct, additional efforts for examining the broader construct as well as its component parts are still needed in order to better account for their predictive value when identifying a high-risk profile of problematic youths [23]. Although there are measures for child psychopathy, no measures exist to tap all components at once while also including CD criteria. To this end, the Proposed Specifiers for Conduct Disorder (PSCD) [6] has been developed as a measure of the broader psychopathy construct from early childhood to late adolescence, including CD. The PSCD is composed of 24 items, addressing four dimensions (specifiers) that include the interpersonal (i.e., GM), affective (i.e., CU) and lifestyle (i.e., DI) dimensions of psychopathic personality, in addition to CD. Item selection for the PSCD was performed using both rational and empirical criteria and according to three main premises: (1) to provide a measure of the three-factor model of psychopathic personality plus CD in a way that closely resembles how it is often conceptualized in adolescence and adulthood [2], but also including only those traits with an empirical and/or theoretical support for being identifiable at early developmental stages [7, 23]; (2) to increase the homogeneity within scales with item selection focused on content representativeness and item harmonization [9]. This latter point was to only include items that did not contradict one another (e.g., impulsive vs. planful/manipulative); and, (3) to include the four criteria for $\mathrm{CD}$, plus one oppositional defiant disorder (ODD) item.
There are initial signs that the PSCD is a promising measure $[12,15]$. For instance, the PSCD was preliminary validated in a sample of 2,229 preschool children, with information provided by parents [12]. Confirmatory factor analyses supported both three- and four-factor structures. The validity of the PSCD was also supported by convergent and divergent associations with an alternative measure of psychopathic traits as well as by the expected relations with fearlessness, conduct problems, reactive and proactive aggression, attention-deficit hyperactivity disorder, ODD, and social competence skills. In a second study, the PSCD self-report version was examined in two samples of Portuguese youths [24], including a community sample of boys and girls $(n=648)$, and a sample of boys from forensic settings $(n=258)$. Results overall supported the PSCD as representing both a general factor and four specific factors (GM, CU, DI, CD), and provided evidence for reliability, construct, and temporal validity. Finally, the psychometric properties of the self-reported version of the PSCD were also examined in a community sample of 1,683 Chinese adolescents [15]. Again, the results supported the four-factor structure of the PSCD, which better fitted in a bifactor structure. The authors also proposed a short version (PSCD-SV) including 13 items with substantial item reliability, which provided further support for a four-factor interrelated model, being in line with the initial conceptualization of the PSCD. Also, the short version provided an even better fit to the data and identified a significantly higher proportion of youths with elevated psychopathic traits, suggesting that the short version slightly outperformed the standard version, at least at the psychometric level. Finally, both standard and short versions exhibited the expected relations with other psychopathy measures, anxiety and depression, and aggression.

Overall, results obtained to date with the PSCD suggest that youth psychopathy is a multifaceted construct that can be modeled with $\mathrm{CD}$ as originally proposed with important relations with external theoretically meaningful variables [9, 23]. Although the PSCD seems a promising measure, much more research is needed given that very few studies exist on the PSCD. Research that continues to evaluate the psychometric properties of the PSCD, especially research that expands on the examination of external correlates and potential developmental precursors, will help to build the knowledge base for this relatively new, and only minimally investigated, PSCD measure.

\section{Developmental Precursors of Psychopathic Personality: The Role of Parenting}

The relevance of psychopathic traits for long-lasting behavioral and psychosocial problems makes it a necessary consideration to better understanding their development by examining some pertinent precursors. That is, although biological (i.e., 
genetics) [25] and temperamental factors (i.e., fearlessness) $[26,27]$, have been extensively highlighted as early underpinnings of psychopathic personality, from a developmental psychopathology approach environmental influences (e.g., parenting practices) should also be considered as potential markers of psychopathic traits [28] as they may shed light on the mechanisms of change that may influence their later development across lifespan [9]. However, at the child level, studies on parenting practices appears to mainly be focused on only one component of psychopathy, namely CU traits. And, even then, the parenting practices are only moderately investigated. This makes it difficult to know how the broader concept and its individual components may related to parenting practice and underscores the need for multidimensional measures like the PSCD to fill this void.

As was consistently observed for behavioral problems [29-33], dysfunctional parenting practices, including inconsistent, harsh and coercive practices in addition to low warmth, support, affection and acceptance, emerge as relevant factors in predicting changes in psychopathic traits across childhood and adolescence [9, 34, 35], for comprehensive reviews]. Parental warmth, responsiveness or acceptance has been used to refer to the support dimension of parenting (parental support, from now on) that represents parenting behaviors that make the child feel loved, accepted and approved [30]. Results from previous research showed that an infrequent use of practices based on warmth, acceptance and involvement was related with higher levels of CU traits [36-38]. Moreover, adolescents high on CU traits reported low parent-child involvement [39, 40], low monitoring [39, 41], deficient parent-child communication patterns [40] as well as low autonomy transfer, and high levels of harsh parenting $[42,43]$. Furthermore, overall psychopathic and more specific CU traits were found as moderators in the relationship between parenting practices and adolescent outcomes and behaviors [44-48].

As noted, since current conceptualizations of youth psychopathy encourage a multidimensional approach to the construct [6,9], new studies aimed at disentangling the effect of different parenting dimensions on each psychopathy dimension will help to better understand the environmental contribution to their development across time. Previous studies in this regard did not show significant associations between harsh and inconsistent parenting and any of the four psychopathic facets assessed by means of the PCL-YV [49]. Also, the study carried out by Chinchilla and Kosson [44] did not find a significant association between parental warmth and the interpersonal and affective facets of psychopathy; however, they found a significant association with the total PCLYV. Most of these studies did not longitudinally analyze the relationship between parenting and psychopathic traits, which prevents the consideration of parenting as a precursor of psychopathy. To disentangle the effects between parental behavior and psychopathic traits over time, Salihovic et al. [50] conducted a longitudinal study in Sweden. In this study, negative parental practices, such as parent's negative reactions to disclosure, and positive parenting reactions, such as attempted understanding, predicted change in adolescent psychopathic traits over time as revealed by a cross-lagged panel model. More recently, Backman et al. [51] observed in a large sample of offending adolescents that adolescent self-reported parental warmth was associated with lower psychopathic traits, whereas high hostility was predictive of higher psychopathic traits. However, they used a global score for psychopathic traits, which did not allow to explore which dimension(s) particularly accounted for those associations. Therefore, further research is needed in order to elucidate which parenting factors and processes are specifically linked to overall psychopathic personality and each particular dimension, promoting either stability or change, and providing new insight for theoretical understanding, prevention targets, risk assessment, and intervention designs.

\section{This Study}

The present study was developed with the primary purpose of further examining the psychometric properties of the PSCD-SV including its factor structure, reliability, and convergent associations of the PSCD-SV scales and Total scores with a wide range of behavioral, emotional and psychosocial variables traditionally shown to be related with the psychopathy construct, but barely examined when using the PSCD thus far (e.g., externalizing and internalizing problems, and antisocial behavior). This study builds on past research with the PSCD with the examination of the parenting variables which offers a new and needed area of investigation for both psychometric investigation purposes but also potential etiological theory development. The parental component of the study is measured at two time points providing a longitudinal component to the investigation. In addition, this study focused on the short version of the PSCD, given that there is a need for brief measures of psychopathy for research purposes [12]. The usefulness and increasing need of short scales for measuring personality traits has been widely recognized [52], since they facilitate data collection (e.g., screening studies, large-scale surveys) in a cost-effective manner [15]. In sum, the psychometric properties of the PSCD-SV, including factor structure and internal consistency, were preliminary examined in a sample of adolescents, followed by convergent validity and an examination of parental variables in a longitudinal design. Although the PSCD has some preliminary data to support its use, we expected in the current study that it would show adequate psychometric properties, before drawing developmental conclusions on the parenting variables. 
The following hypotheses were proposed: (1) a better fit for the four-factor model in regard to the internal structure of the PSCD is expected, which resembles the four dimensions encompassed in the construct of psychopathy (i.e., GM, CU, DI, and CD); (2) the PSCD-SV was expected to show good internal consistency for a short scale; (3) these psychopathic traits were also expected to show positive associations with behavioral, emotional, and psychosocial problems, including antisocial behavior, as well as positive relationships with parenting practices such as psychological control and negative associations with parental support, backing the convergent validity of the scale; and (4) parenting practices were expected to longitudinally and distinctively predict the four-psychopathy dimensions in a two-year period. Specifically, it was expected that both psychological control and parental support would strongly predict the affective facet of psychopathy (i.e., CU) as well as CD, whilst significant differential associations are also expected for GM and DI.

\section{Methods}

\section{Participants}

The sample used in the current study is part of a three-year longitudinal study which was conducted in the Autonomous Community of Galicia (NW Spain) between 2017 and 2019. The initial sample included a total of 642 adolescents in the first grade of compulsory secondary education $\left[1^{\circ} \mathrm{ESO}\right]$ from 11 state secondary schools. Participants in T1 ranged in age from 12 to $15(M=12.49 ; S D=0.67)$, and $45.4 \%$ were females. The second wave that took place one-year after the first assessment (T2) included a total of 625 adolescents aged 13-17 $(M=13.43 ; S D=0.68)$, of which $47.5 \%$ were females. Finally, a total of 627 adolescents took part in the third wave which was carried out 2 years after the first assessment (T3). Participants in T3 aged $14-18(M=14.42 ; S D=0.68), 48.6 \%$ females, and were involved in the third grade of compulsory secondary education $\left[3^{\circ} \mathrm{ESO}\right.$ ]. It should be noted that second and third waves included not only participants assessed at the first wave but also new participants that met the criteria for their inclusion in the study. For the purposes of the current study, only adolescents who were assessed at T1 and followedup at T3 were included in the analysis. This gave rise to a total sample of 414 adolescents aged 12-15 at the first assessment ( $M=12.32 ; S D=0.50 ; 49.2 \%$ females $)$, which was followed up 2 years later when participants were in third grade $(M=14.18$; $S D=0.40)$. Most of participants lived with both parents at T1 $(84.7 \%)$, whereas $12.1 \%$ lived only with their mother, $1.9 \%$ lived only with their father, and $1.2 \%$ lived with other relatives. More than $90 \%$ of the sample were Galician, white, and came from middle and low-middle socio-economic backgrounds.

\section{Measures}

\section{Psychopathic Traits (T3)}

The Proposed Specifiers for Conduct Disorder-Short Version (PSCD-SV) [6, 15] was used for the self-reported assessment of psychopathic traits. The short version of the PSCD was developed by retaining 13 items from the original PSCD with substantial item reliability for the three psychopathy dimensions: GM (3 items, e.g., "Lying is easy for me"), CU (3 items, e.g., "I don't waste time thinking about how I may have hurt others"), and DI (3 items, e.g., "I get a thrill out of doing risky things"); and the four CD subtype items (4 items, e.g., "I have stolen things") (15)]. The PSCD-SV was rated by participants using a 3 -point scale $(0=$ not true, $1=$ sometimes true, $2=$ true). Additional information about the items, factor loadings and reliability of the factors are presented in Tables 1 and 2 and the "Results" section.

Parental support (T1-T3)

The perception of parental warmth, responsiveness, and closeness to parents was assessed by means of the selfreported Affection and Communication scale, developed and validated in community Spanish adolescents as part of a larger parenting questionnaire [53], and used in previous studies with the current sample [54]. The scale is composed of 8 items (e.g., "You feel supported and understood") scored in a 4-point scale ranging from 0 (never) to 3 (always). The internal consistency of the scale (i.e., Cronbach's alpha) for the total sample was 0.89 in the first wave (Mean Inter-item Correlations $[\mathrm{MIC}]=0.70$ ) and 0.91 in the third wave of study $(\mathrm{MIC}=0.72)$.

\section{Psychological Control (T1-T3)}

Also included in the parenting questionnaire developed and validated by Oliva et al. [53], the self-reported Psychological Control scale, was used for the assessment of parental psychological control, defined as the use of psychological coercion and emotional manipulation through which parents seek to control or manage their children's behavior. The scale was composed of 8 items (e.g., "Your parents make you feel guilty when you don't do what they want") which ranged from 0 (never) to 3 (always). The Cronbach's alpha for the total sample was 0.86 in the first wave $(\mathrm{MIC}=0.62)$ and 0.89 in the third wave $(\mathrm{MIC}=0.66)$.

\section{Psychosocial Adjustment (T3)}

The Spanish self-reported version of the Strengths and Difficulties Questionnaire (SDQ) [55, 56] was used for the 
Table 1 Descriptive statistics for main study variables

\begin{tabular}{|c|c|c|c|c|}
\hline & \multirow[t]{2}{*}{ Mean } & \multirow[t]{2}{*}{ SD } & \multicolumn{2}{|c|}{ Range $^{\mathrm{a}}$} \\
\hline & & & Min & $\operatorname{Max}$ \\
\hline \multicolumn{5}{|l|}{$\mathrm{T} 1$ variables } \\
\hline \multicolumn{5}{|l|}{ Parenting } \\
\hline Support & 2.47 & 0.58 & 0.00 & 3.00 \\
\hline Psychological control & 0.90 & 0.65 & 0.00 & 3.00 \\
\hline Antisocial behavior & 0.48 & 0.97 & 0.00 & 7.75 \\
\hline \multicolumn{5}{|l|}{$\mathrm{T} 3$ variables } \\
\hline \multicolumn{5}{|l|}{ PSCD-SV } \\
\hline GM & 0.37 & 0.36 & 0.00 & 2.00 \\
\hline $\mathrm{CU}$ & 0.23 & 0.33 & 0.00 & 1.67 \\
\hline DI & 0.82 & 0.56 & 0.00 & 2.00 \\
\hline $\mathrm{CD}$ & 0.19 & 0.32 & 0.00 & 1.75 \\
\hline Total score & 0.35 & 0.27 & 0.00 & 1.62 \\
\hline \multicolumn{5}{|l|}{ SDQ } \\
\hline Conduct problems & 0.32 & 0.30 & 0.00 & 1.40 \\
\hline Emotional problems & 0.60 & 0.48 & 0.00 & 2.00 \\
\hline Hyperactivity & 0.85 & 0.48 & 0.00 & 2.00 \\
\hline Peer problems & 0.28 & 0.29 & 0.00 & 1.40 \\
\hline Prosocial behavior & 1.58 & 0.34 & 0.40 & 2.00 \\
\hline \multicolumn{5}{|l|}{ ABQ } \\
\hline Aggressive behavior & 0.07 & 0.20 & 0.00 & 1.83 \\
\hline Rule-breaking & 0.21 & 0.33 & 0.00 & 3.00 \\
\hline Theft & 0.09 & 0.23 & 0.00 & 2.17 \\
\hline Vandalism & 0.07 & 0.20 & 0.00 & 1.67 \\
\hline \multicolumn{5}{|l|}{ Parenting } \\
\hline Support & 2.21 & 0.64 & 0.00 & 3.00 \\
\hline Psychological control & 1.13 & 0.71 & 0.00 & 2.88 \\
\hline
\end{tabular}

$P S C D-S V$ Proposed Specifiers for Conduct Disorder-Short Version, $G M$ grandiose-manipulative, $C U$ callous-unemotional, $D I$ daringimpulsive, $C D$ conduct disorder, $S D Q$ Strengths and Difficulties Questionnaire, $A B Q$ Antisocial Behavior Questionnaire

${ }^{a}$ Range of mean scores for each analyzed variable in the current sample

assessment of the adolescent psychosocial functioning. The SDQ is composed of 25 items intended to assess five different psychosocial domains (each with five items): Emotional symptoms (e.g., "I am often unhappy, depressed or tearful", $\alpha=0.73, \mathrm{MIC}=0.50$ ), Conduct problems (e.g., "I fight a lot. I can make other people do what I want", $\alpha=0.49$, MIC = 0.28), Hyperactivity (e.g., "I am easily distracted, I find it difficult to concentrate", $\alpha=0.69, \mathrm{MIC}=0.45$ ), Peer problems (e.g., "Other children or young people pick on me or bully me", $\alpha=0.51$, MIC $=0.29$ ), and Prosocial behavior (e.g., "I am helpful if someone is hurt, upset or feeling ill", $\alpha=0.63$, MIC $=0.39$ ). The response format ranged in a 3-point scale from 1 (not true) to 3 (certainly true).

\section{Antisocial Behavior (T1-T3)}

Problematic behavior was assessed by means of the Antisocial Behavior Questionnaire (ABQ) [57]. Four subscales (6 items each) were included in this study (T3): aggression (e.g., "Fighting and hitting someone"; $\alpha=0.72, \mathrm{MIC}=0.50$ ), rule-breaking behavior (e.g., "Spending the night out without permission"; $\alpha=0.63$, MIC $=0.38$ ), theft (e.g., "Taking something from class without permission with the intention of stealing it"; $\alpha=0.63$, MIC $=0.38$ ), and vandalism (e.g., "Setting fire to something: a bin, table, car, etc."; $\alpha=0.63$, $\mathrm{MIC}=0.38$ ). A composite mean score was created with the scales measured in $\mathrm{T} 1$ to be included as covariate in the SEM models $(\alpha=0.77, \mathrm{MIC}=0.59)$. All the items were scored in a 4-point scale which ranged from 0 (never) to 3 (very often).

\section{Procedure}

The procedure followed throughout the investigation was in compliance with the standards of the University Ethics Committee and the Declaration of Helsinki. Following a convenience sampling approach, the heads of 24 secondary schools were initially contacted by phone to present the study and ask for potential collaboration. Schools located in the four provinces of the Autonomous Community, and representative of this area, were contacted. A brief report with more detailed information about the research project and the goals of the study were sent by mail to all those interested in taking part in. Specifically, the main goal of this longitudinal study was to delve into the role that certain parenting practices have on adolescent development, as well as the interactional effect with other factors such as peers or personality traits. Hence, to analyze the psychosocial development from early adolescence, the target population of study encompassed all students involved in the first degree of secondary education at the beginning of the project. After the first contact, a total of 11 secondary schools agreed to participate in the longitudinal study. Qualified psychologists from the research group visited all the schools to explain the procedures and solve any doubts that may arise regarding the prospective study. Parental consent was requested each year before the beginning of data collection and, subsequently, adolescent assent was obtained during questionnaire implementations. Given that informed consent was annually requested, no restrictions regarding new participations were made for their inclusion in the study. Data collection was conducted by qualified research assistants, who visited the centers during school hours in order to provide proper instructions to the adolescents and monitor the process. Adolescents filled out the questionnaires in group sessions of approximately $50 \mathrm{~min}$ in classroom. Adolescent participation was voluntary, and confidentiality was guaranteed following the ethical criteria. Personal but anonymous codes were used to link questionnaires' information from different waves of 
study. A total of three waves of data collection were carried out during a three-year period, with intervals of approximately 12 months between follow-ups.

\section{Data Analysis}

Descriptive statistics for main study variables were first examined in SPSS 25. Second, in order to replicate the factorial structure of the short version of the PSCD proposed by Luo et al. [15], a Confirmatory Factor Analysis (CFA) was conducted in Mplus 7.4 [58], with robust weighted least squares used as estimator (WLSMV). A four-factor interrelated and a four-factor superordinate model were specified, including the 13 items as observed variables and psychopathy as a second order factor. Model fit was assessed using root-mean-square error of approximation (RMSEA), comparative fit index (CFI), and the Tucker-Lewis index (TLI). According to $\mathrm{Hu}$ and Bentler [59] suggestions, RMSEA values lower or equal to 0.05 , and TLI and CFI values of 0.95 or higher were considered indicators of good model fit, whereas a RMSEA smaller than 0.08, and TLI and CFI larger than 0.90 indicated adequate model fit. Internal consistency of the PSCD-SV total score was computed with Cronbach's alpha $(\alpha)$. However, given the dependence of alpha on the number of items in a scale, as well as other concerns about its reliance (e.g., the normal distribution of items) [60], mean inter-item correlation (MIC) was computed as a more appropriate indicator of the internal consistency for the PSCD-SV subscales (i.e., 3 items per subscale), with values ranging from 0.15 to 0.50 being considered adequate [61]. Concurrent associations of the PSCD factors and Total score with external variables measuring behavioural, emotional and psychosocial problems, antisocial behaviour and parenting practices were examined by computing zero-order correlations in SPSS 25. Partial correlations controlling for age and gender were computed for PSCD Total. For each PSCD factor, we also computed partial correlations controlling for the effect of gender, age and the other three PSCD factors. In this way, we were able to examine the differential associations of each PSCD factor with external criteria, above and beyond the shared variance among dimensions. To counteract the issue of multiple testing, Bonferroni's correction was applied, and the threshold levels of significance were settled at 0.005 (11 variables). Finally, a Structural Equation Model (SEM) was computed in Mplus 7.4 using WLSMV as estimator, to analyze the influence of parenting practices in early adolescence on psychopathic traits 2 years later, including both parental support and parental psychological control as latent variables predicting the four latent psychopathic factors. SEM controlled for age and gender of the participants, people they lived with (coexistence), and antisocial behavior in $\mathrm{T} 1$. All models adjusted statistically for the school-level clustering of data and used listwise to manage missing data.

\section{Results}

\section{The PSCD-SV: Psychometric Properties}

The four-factor model of the PSCD-SV showed an acceptable-to-good model fit, $\chi^{2}(60)=100.92, p^{<}$
Table 2 Item loadings for the four-factor solution (CFA) of the PSCD-Short Version

\begin{tabular}{|c|c|c|c|c|}
\hline & GM & $\mathrm{CU}$ & DI & $\mathrm{CD}$ \\
\hline \multicolumn{5}{|l|}{ Item } \\
\hline 1. Lying is easy for me & 0.77 & & & \\
\hline 2. I take advantage of others & 0.78 & & & \\
\hline 3. I am a good storyteller & 0.42 & & & \\
\hline 4. I don't waste time thinking about how others feel & & 0.61 & & \\
\hline 5. When people are happy or upset I don't seem to care & & 0.59 & & \\
\hline 6. I like it when others are afraid of me & & 0.71 & & \\
\hline 7. I like a lot of change or adventure & & & 0.40 & \\
\hline 8. I get a thrill out of doing risky things & & & 0.63 & \\
\hline 9. I feel like I need a lot of stimulation & & & 0.71 & \\
\hline 10. I have stolen things & & & & 0.85 \\
\hline $\begin{array}{l}\text { 11. I have engaged in physical aggression against animals or } \\
\text { people }\end{array}$ & & & & 0.59 \\
\hline 12. I have destroyed property & & & & 0.72 \\
\hline 13. Some people say I break a lot of rules & & & & 0.67 \\
\hline Factor loadings on total score & 0.85 & 0.66 & 0.66 & 0.94 \\
\hline
\end{tabular}

PSCD Proposed Specifiers for Conduct Disorders, CFA confirmatory factor analysis, $G M$ grandiose/deceitful, $C U$ callous-unemotional, $D I$ daring/impulsive, $C D$ conduct disorder. All factor loadings were statistically significant at $p<0.001$ 


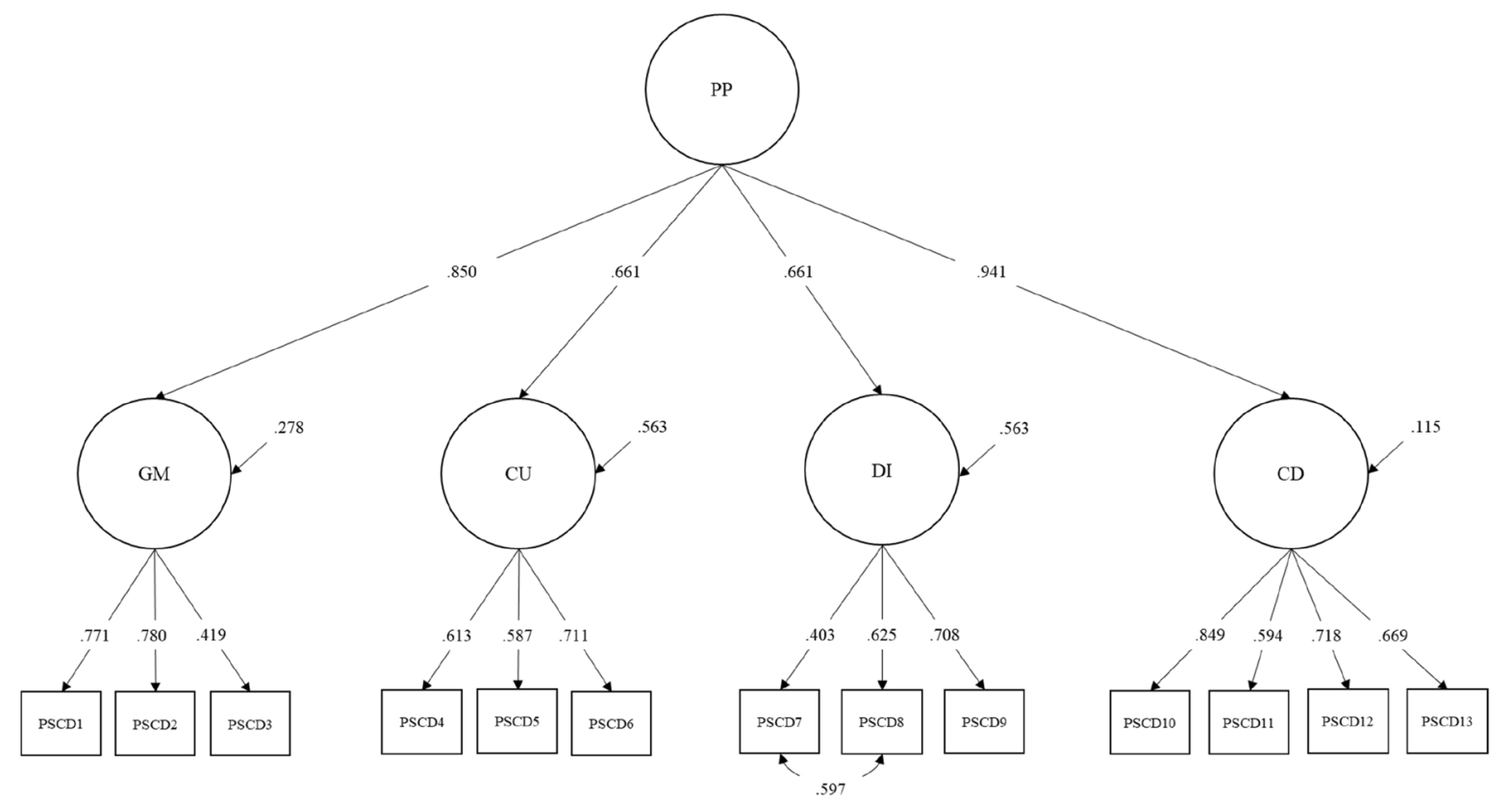

Fig. 1 Standardized model parameters for the four-factor superordinate model of the Proposed Specifiers for Conduct Disorder-Short Version (PSCD-SV). PP Psychopathic Personality, GM grandiose/ deceitful, $C U$ callous-unemotional, $D I$ daring/impulsive, $C D$ conduct disorder, PSCD Proposed Specifiers for Conduct Disorder. Fit indi-

$0.001, \mathrm{CFI}=0.94, \mathrm{TLI}=0.92, \mathrm{RMSEA}=0.05[0.04$, $0.07]$. The four-factor model was better than the onefactor model, $\chi^{2}(65)=313.14, p<0.001, \mathrm{CFI}=0.78$, $\mathrm{TLI}=0.73$, RMSEA $=0.10$, and the three-factor model $\chi^{2}(24)=74.11, p^{<} 0.001, \mathrm{CFI}=0.93, \mathrm{TLI}=0.89$, RMSEA $=0.07$. Modification indices substantiated a residual covariance between items 15 and 14 as representing an acutely misspecified parameter in the model. After including this new parameter, a good model fit was observed for the four-factor model, $\chi^{2}(60)=100.92, p^{<}$ $0.001 ; \mathrm{CFI}=0.96, \mathrm{TLI}=0.95, \mathrm{RMSEA}=0.04[0.03,0.05]$. Equal model fit indices were obtained for the two alternative four-factor interrelated and four-factor superordinate models (see Fig. 1 for a representation of the four-factor superordinate model). As can be observed in Table 2, all 13 items loaded significantly on the expected PSCD factor and the latent global construct, with all item and factor loadings being above 0.40 .

In terms of internal consistency, Cronbach's alpha was 0.73 for the PSCD Total score. Given the very low level of number of items for the subscales, we utilized the MIC to further examine scale homogeneity. All MIC values were indicative of an adequate internal consistency for all the PSCD factors (MIC $=0.30,0.28,0.47,0.43$ for GM, CU, DI, and CD respectively). The MIC for the Total score also showed good homogeneity $(\mathrm{MIC}=0.35)$. Significant correlations $(p<0.001)$ were observed between the PSCD ces and factor loadings were equivalent between the superordinate and the four-factor interrelated models. In the four-factor interrelated, all PSCD-SV dimensions were significantly correlated $\left(p^{<} 0.001\right)$ : $\mathrm{GM}-\mathrm{CU}=0.60 ; \mathrm{GM}-\mathrm{DI}=0.57 ; \mathrm{GM}-\mathrm{CD}=0.78 ; \mathrm{CU}-\mathrm{DI}=0.36$; $\mathrm{CU}-$ $\mathrm{CD}=0.63 ; \mathrm{DI}-\mathrm{CD}=0.65$

Total score and the four PSCD factors $\left(\mathrm{r}^{\prime} \mathrm{s}=0.69^{\mathrm{GM}} ; 0.55^{\mathrm{CU}}\right.$; $0.73^{\mathrm{DI}} ; 0.74^{\mathrm{CD}}$ ).

\section{Concurrent Associations Between Psychopathic Traits and External Criteria}

As displayed in Table 3, the PSCD Total score was significantly correlated with all analyzed variables. At the zeroorder level, all PSCD factors showed significant correlations with conduct problems and all facets of antisocial behavior. DI and CD traits were significantly correlated with emotional problems and hyperactivity, which was also related with the GM factor. All GM, CU and CD factors were negatively correlated with prosocial behavior, whilst only $\mathrm{CU}$ traits showed a significant correlation with peer problems. With respect to parenting practices, GM, CU, and CD factors were negatively correlated with parental support, whilst only GM and CD significantly correlated with psychological control.

When controlling for the effect of the other psychopathic traits, the GM factor remained significantly correlated with conduct problems, hyperactivity, prosocial behavior, and parental support (both inversely) and psychological control (see Table 3). The CU factor, in contrast, only showed a unique significant (inverse) correlation with prosocial behavior. The DI factor remained significantly correlated with conduct problems, hyperactivity, and rule breaking. Finally, the CD factor remained significantly correlated with conduct 


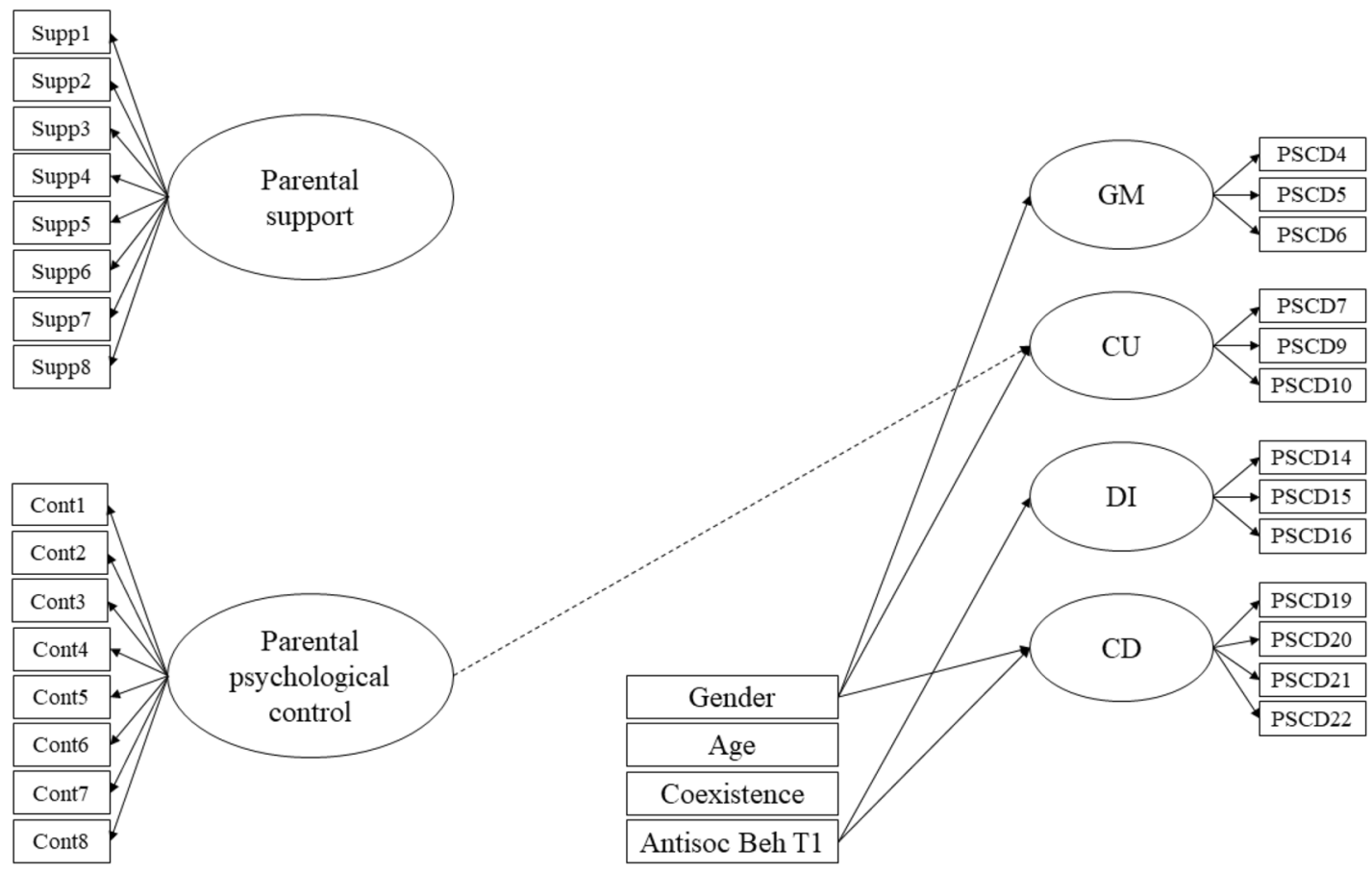

Fig. 2 Significant results of the SEM parenting model predicting psychopathic traits. Dotted line represents significant relationships in nonstandardized results. GM Grandiose/deceitful, $C U$ Callous-unemotional, DI Daring/Impulsive, $C D$ conduct disorder

Table 3 Concurrent (T3) zero-order and partial correlations (controlling for the other three PSCD subscales), between the PSCD subscales and total score and external criteria

\begin{tabular}{|c|c|c|c|c|c|}
\hline & \multicolumn{5}{|l|}{ PSCD } \\
\hline & $\mathrm{GM}^{\mathrm{a}}$ & $\mathrm{CU}^{\mathrm{a}}$ & $\mathrm{DI}^{\mathrm{a}}$ & $\mathrm{CD}^{\mathrm{a}}$ & Total score \\
\hline \multicolumn{6}{|l|}{ SDQ } \\
\hline Conduct problems & $0.48 *(0.30 *)$ & $0.25 *(0.07)$ & $0.33 *(0.17 *)$ & $0.49 *(0.31 *)$ & $0.56^{*}$ \\
\hline Emotional problems & $0.13(0.07)$ & $0.07(0.02)$ & $0.11 *(0.05)$ & $0.14 *(0.07)$ & $0.17 *$ \\
\hline Hyperactivity & $0.32 *(0.17 *)$ & $0.10(-0.05)$ & $0.36^{*}\left(0.26^{*}\right)$ & $0.33 *(0.18 *)$ & $0.42 *$ \\
\hline Peer problems & $0.12(0.08)$ & $0.16^{*}(0.13)$ & $0.04(0.00)$ & $0.09(0.01)$ & $0.14 *$ \\
\hline Prosocial behavior & $-0.24 *(-0.14 *)$ & $-0.31 *(-0.24 *)$ & $-0.01(0.12)$ & $-0.25^{*}(-0.13)$ & $-0.26^{*}$ \\
\hline \multicolumn{6}{|l|}{$\mathrm{ABQ}$} \\
\hline Aggressive behavior & $0.20 *(-0.03)$ & $0.24 *(0.12)$ & $0.15^{*}(0.01)$ & $0.47 *(0.41 *)$ & $0.38 *$ \\
\hline Rule-breaking & $0.26 *(0.03)$ & $0.17 *(0.03)$ & $0.32 *(0.20 *)$ & $0.46^{*}\left(0.35^{*}\right)$ & $0.45^{*}$ \\
\hline Theft & $0.28 *(-0.02)$ & $0.24 *(0.10)$ & $0.27 *(0.12)$ & $0.57 *(0.48 *)$ & $0.50^{*}$ \\
\hline Vandalism & $0.21 *(0.01)$ & $0.26 *(0.12)$ & $0.24 *(0.13)$ & $0.38 *(0.30 *)$ & $0.39 *$ \\
\hline \multicolumn{6}{|l|}{ Parenting } \\
\hline Support & $-0.24^{*}\left(-0.14^{*}\right)$ & $-0.15^{*}(-0.05)$ & $-0.11(-0.01)$ & $-0.25^{*}\left(-0.15^{*}\right)$ & $-0.26^{*}$ \\
\hline Psychological control & $0.24 *(0.15 *)$ & $0.09(0.01)$ & $0.11(0.12)$ & $0.24 *(0.14 *)$ & $0.24 *$ \\
\hline
\end{tabular}

$P S C D$ Proposed Specifiers for Conduct Disorder, $G M$ grandiose-manipulative, $C U$ callous-unemotional, $D I$ daring-impulsive, $C D$ conduct disorder, $S D Q$ Strengths and Difficulties Questionnaire, $A B Q$ Antisocial Behavior Questionnaire

${ }^{\text {a }}$ Partial correlations controlling for the other three PSCD factors

*Significant $p$ value after applying Bonferroni correction $(p<0.005)$ 
problems, hyperactivity, all facets of antisocial behavior, and both parenting practices.

\section{Examining the PSCD Construct Validity via Longitudinal Effects of Parenting on Psychopathic Traits}

A SEM model was conducted to predict PSCD psychopathic traits two years following the initial assessment, including both parental support and psychological control as predictors. For methodological issues, the SEM model was based on the four-factor interrelated model of the PSCD-SV, allowing to test the unique association between parenting predictors and later psychopathic traits. This model, statistically equivalent than the four-factor superordinate model, provided a more parsimonious solution to be accommodated in SEM. In order to preliminary test the independent contribution of each parenting practice, two independent models were also tested. One included parental support as independent predictor of later psychopathic traits, $\chi^{2}(241)=264.41$, $p=0.144, \mathrm{CFI}=0.96, \mathrm{TLI}=0.95, \mathrm{RMSEA}=0.02[0.00$, 0.03 ], showing that support significantly predicted lower levels of GM $(\beta=-0.27), \mathrm{CU}(\beta=-0.27)$, and $\mathrm{CD}$ $(\beta=-0.14)$. An alternative model included psychological control as T1 predictor $\chi^{2}(242)=269.63, p=0.107$, $\mathrm{CFI}=0.96$, TLI $=0.95$, RMSEA $=0.02[0.00,0.03]$, showing that it significantly predicted higher levels of $\mathrm{CU}$ $(\beta=0.28)$ and $\mathrm{CD}(\beta=0.18)$ (further details are available upon request). The integrated model, including both support and control, exhibited an adequate fit, $\chi^{2}(452)=486.14$, $p=0.129, \mathrm{CFI}=0.97, \mathrm{TLI}=0.96, \mathrm{RMSEA}=0.01[0.00$,
$0.02]$. with all psychopathic traits being significantly correlated $\left(r\right.$ 's $=0.72^{\mathrm{GM}-\mathrm{CU}} ; 0.59^{\mathrm{GM}-\mathrm{DI}} ; 0.75^{\mathrm{GM}-\mathrm{CD}} ; 0.41^{\mathrm{CU}-\mathrm{DI}}$; $\left.0.60^{\mathrm{CU}-\mathrm{CD}} ; 0.66^{\mathrm{DI}-\mathrm{CD}} ; p \mathrm{~s}<0.001\right)$. Table 4 displays the unstandardized and standardized results of this model, as well as the explained variance. Gender (being male) significantly predicted GM, CU, and CD, and antisocial behavior at $\mathrm{T} 1$ significantly predicted higher levels of DI and CD. However, including both parenting practices $(r=-0.58$, $p<0.001)$ did not reveal a significant effect on later psychopathic traits, as observed for the non-significant standardized effects of parenting practices on psychopathic traits. Only the unstandardized effect of psychological control on $\mathrm{CU}$ was statistically significant (Fig. 2).

\section{Discussion}

Psychopathic personality has shown its usefulness as a relevant predictor, and potential identifier, of more severe and pervasive forms of youth behavioral and psychosocial maladjustment, including conduct problems, aggression, antisocial behavior or low prosocial behavior. Although there is evidence to support the three- and four-factor models of psychopathy in adulthood [1], there is still a need to accurately address the multidimensional construct of psychopathy, by depicting the broader construct while addressing all its dimensions in childhood and adolescence [9, 23, 62, 63]. To this end, it is important to base our research on valid and useful measures that will help to advancing our knowledge on description, etiology, and developmental course of psychopathic personality across the lifespan. To this end, this study focused on the psychometric properties and external validity of the PSCD-SV, which was designed to assess the three dimensions of psychopathy plus $\mathrm{CD}$ with a short form.

Table 4 Results of the SEM parenting model (T1) predicting psychopathic traits (T3)

\begin{tabular}{|c|c|c|c|c|c|c|c|c|}
\hline & \multicolumn{2}{|l|}{ GM } & \multicolumn{2}{|l|}{$\mathrm{CU}$} & \multicolumn{2}{|l|}{ DI } & \multicolumn{2}{|l|}{$\mathrm{CD}$} \\
\hline & Beta $(S E)$ & $\beta$ & Beta $(S E)$ & $\beta$ & Beta $(S E)$ & $\beta$ & Beta $(S E)$ & $\beta$ \\
\hline Gender & $-0.25(0.10)^{* *}$ & $-0.18 * *$ & $-0.41(0.09)^{* * *}$ & $-0.35 * * *$ & $-0.02(0.09)$ & -0.03 & $-0.54(0.08)^{* * *}$ & $-0.32 * * *$ \\
\hline Age & $0.02(0.08)$ & 0.02 & $-0.10(0.13)$ & -0.08 & $-0.05(0.07)$ & -0.06 & $0.07(0.08)$ & 0.04 \\
\hline Coexistence & $-0.17(0.11)$ & -0.10 & $0.12(0.11)$ & 0.09 & $-0.05(0.05)$ & -0.06 & $0.10(0.10)$ & 0.05 \\
\hline Antisocial behavior & $0.05(0.06)$ & 0.07 & $0.02(0.04)$ & 0.04 & $0.10(0.02)^{* * *}$ & $0.24 * * *$ & $0.14(0.04)^{* * *}$ & $0.16^{* * *}$ \\
\hline Parental support & $-0.39(0.20)$ & -0.27 & $-0.23(0.14)$ & -0.19 & $-0.08(0.08)$ & -0.09 & $-0.14(0.14)$ & -0.08 \\
\hline Psychological control & $0.01(0.15)$ & 0.01 & $0.16(0.08)^{*}$ & 0.18 & $-0.02(0.07)$ & -0.04 & $0.18(0.10)$ & 0.14 \\
\hline $\mathrm{R}^{2}$ & 0.15 & & 0.26 & & 0.08 & & 0.23 & \\
\hline
\end{tabular}

$G M$ grandiose-manipulative, $C U$ callous-unemotional, $D I$ daring-impulsive, $C D$ conduct disorder

The independent variables were measured at $\mathrm{T} 1$ and the dependent variables were measured at T3. Gender was coded 0 -male, $1-$ female. Factor loadings of parental support ranged from 0.60 to 0.81 . Factor loadings of psychological control, from 0.57 to 0.77 . After applying the listwise option to manage missing data, $n=373$. Models included the correlations between PSCD15-PSCD14 and SUPPORT2-SUPPORT1 as modification indices

$* * * p<0.001 ; * * p<0.01 ; * p<0.05$ 


\section{The PSCD-SV}

The present study aimed to provide new evidence on the psychometric properties of the PSCD [6] and, more specifically, the self-reported short version (PSCD-SV) first examined by Luo et al. [15]. The PSCD-SV addresses interpersonal (i.e., GD), affective (i.e., CU) and behavioral/lifestyle (i.e., DI) dimensions of psychopathy, along with the four key CD symptom categories of $\mathrm{CD}$ and one ODD criteria $[9,23$, 64]. According to the original proposal [9]; see also [15], the four-factor structure of the PSCD-SV was supported, representing the three psychopathy dimensions (GM, CU, and DI) along with $\mathrm{CD}$, with an overarching latent hierarchical factor. The standardized factor loadings were overall higher than 0.60 , with only four in the range of $0.40-0.60$, being also supportive of the PSCD as a four-factor measure that distinctively assesses four different but interrelated dimensions of the psychopathic construct $[1,9]$. Due to the low number of items per scale, we relied on the MICs as an estimate of reliability. The MICs for the total and subscale scores were good and therefore supported scale homogeneity.

\section{Psychopathic Traits and External Criteria: Concurrent Associations}

At the zero-order level, both the total score and all the PSCD-SV factors were related with conduct problems and all facets of antisocial behavior [65], and all but one were significantly correlated with hyperactive behaviors (except CU traits) and-inversely-with prosocial behavior (except DI). Only CU traits showed a significant correlation with peer problems [66]. In regards to parenting, GM, CD and the Total score showed significant correlations with both support (inverse) and psychological control, whilst CU traits were negatively correlated with parental support, similar to what has been found in past research [35, 37, 40, 67]. Of note, there was a positive correlation between the Total score and emotional problems, which was essentially driven by DI and CD traits. The co-occurrence between anxiety and CD symptoms have been previously shown in some studies in childhood and adolescence [68], and may partially explain this result. Also, even considering that individuals with psychopathic traits have been traditionally defined as low anxious [69], anxiety and other related emotional problems have been considered as differential indicators of the primary (i.e., low anxious) and secondary variants (i.e., high anxious) of psychopathy, or at least component parts of psychopathy [70], a result that should be further explored in future research.

These results tend to be substantially weaker when controlling for other PSCD-SV factors, reinforcing the assumption that psychopathy dimensions depend at least in part on each other in their relation to external correlates [7]. In this regard, all psychopathic dimensions but one (i.e., $\mathrm{CU}$ traits) remained significantly correlated with conduct problems and hyperactivity. Significant correlations with prosocial behavior held for GM and CU traits. Nevertheless, with regard to antisocial behavior, current results suggest that the $\mathrm{CD}$ factor primarily accounted for most of the correlations between the PSCD factors and external criteria that are antisocial in nature. This possibility has been an issue in some conceptions of the psychopathic construct, in which conduct problems, antisocial behavior, or $\mathrm{CD}$, have been treated as correlates of psychopathic personality instead as fundamental features [71]. However, evidence for the key role of antisocial behaviors in understanding and assessing the psychopathy construct is extensive [1, 9, 72-75]. Moreover, several studies have shown that psychopathic traits are important for predicting several problematic outcomes, even after controlling for severity and the onset of conduct problems [76], or in the absence of concurrent conduct problems $[77,78]$.

Results from partial correlations also contrast with a large body of research based on CU traits as the potential hallmark of the construct of psychopathy, or for being considered as an identifier of a specific group of problematic children showing most serious patterns of conduct problems [79]. Also, once controlling for the effect of the other PSCD-SV psychopathic traits, CU traits only held significantly correlated with prosocial behavior [80], but not with conduct problems, suggesting that when examining CU traits, the effect of the other psychopathy factors should be also taken into account $[7,9]$. In sum, regardless of whether using basic correlations or partial correlations, the correlations offer support for the validity of the PSCD and the multidimensionality of the psychopathy construct. Yet, results from partial correlations should be interpreted with caution since partialling may change variables, being difficult to know "what construct an independent variable represents once the variance shared with other independent variables is removed." [81], p. 329]. Considering psychopathic personality as a constellation of co-occurring interpersonal, affective, and behavioural/lifestyle traits $[1,7,10,16]$, results based on their global and shared contribution should be, therefore, of primary interest.

\section{PSCD-SV and Parenting Practices}

Results from correlations showed a concurrent link between psychopathic traits as measured by the PSCD-SV and parenting practices, reinforcing some results observed in previous research $[82,83]$. Overall, these findings lend further support to the validity of the PSCD-SV. However, the role 
of parenting practices could be understood beyond the concurrent association with psychopathic traits and, therefore, should be examined from a developmental perspective that may lead to better understanding of the potential mechanisms of change in psychopathy development or single component development. As was observed in the present study, parental support, defined as the perception of parental warmth, responsiveness, and closeness to parents, negatively predicted GM and CU traits 2 years later. Also, psychological control, based on psychological coercion and emotional manipulation, significantly predicted later CU traits and $\mathrm{CD}$. These findings largely converge with previous research supporting the association between psychopathic traitsand more specifically CU traits-and an infrequent use of practices based on warmth, acceptance and involvement [36, 84], as well as deficient parent-child communication patterns [40], low autonomy transfer, and high harsh parenting [43]. However, it should be noted that the effect of both parenting practices was no longer significant when they were included together in the model, with just a marginal association between psychological control and CU traits. This points out the importance of taking into account the shared effects between different parenting practices when testing their influence on child's development, and raises the need of further examining the role of parenting in the development of psychopathic traits.

The current results from the PSCD-SV, as a wider set of psychopathic traits and $\mathrm{CD}$, may add to the literature by including the full array of psychopathic traits rather than only focusing in on one of them (i.e., CU traits). Therefore, results showed that not only CU traits, but also GM, could be affected by low parental support, warmth and affection, even after accounting for initial levels of antisocial behavior [35]. Also, the inclusion of psychological control as a predictor variable constitutes a novelty since it has rarely been addressed in previous research on this topic, although it has proved relevant for better understanding adolescent maladjustment [30,33]. Interestingly, when the two parenting variables are included in the model, psychological control remained significantly related with CU traits, yet marginally, raising its importance as a potential developmental precursor of the affective component of psychopathy that should be also considered as a potential target for prevention and intervention purposes.

Notwithstanding these results, it should be noted that the pattern of relationship between parenting practices and psychopathic traits tend to be complex, with psychopathic traits involved in two-way effects with parent-child interactions [85-87], and potential additional moderators affecting those associations [26]. Thereby, it has been suggested that the possible role of psychopathic traits in conferring greater risk for later developing conduct problems and antisocial behavior, might be derived by uniquely shaping dimensions of parenting practices [88], an issue that should be further examined in future research. In this regard, the association between parenting practices and psychopathic traits should be interpreted in the context of potential gene-environment interactions [89], where heritable patterns would potentially underpin the development of psychopathic traits [90], whilst parenting practices would play a role as a potential environmental-mediated predictor of later development of psychopathic traits [91]. To this point, it would be interesting to explore to what extent psychopathic traits in parents may led to parenting practices that exhibit greater levels of harshness or psychological control (as well as reduced parental support and involvement) which, in turn, will influence the development of overall psychopathic and more specific CU traits [92, 93]. Contrastingly, if the parenting seems somewhat "normal," that is free of harshness, harshness does not affect the development of GM or DI then research will need to further explore if there are certain parenting practices that lead to those traits or if the traits are present regardless of the environment. This may mean that the traits come about naturally and are independent of parenting practices. It overall highlights the importance of include environmental factors in the study of psychopathic traits, in order to accurately depict their role in the development of this personality profile and, therefore, their potential usefulness for prevention.

\section{Theoretical and Practical Implications}

The current study has several theoretical and practical implications. First, although much more research is needed, the current results advance the properties of the PSCD-SV as a promising tool to accurately assess psychopathic personality from a multidimensional perspective including $\mathrm{CD}$, which aligns with previous studies on the measure [12,15]. Also in support of its psychometric properties, the PSCD-SV was a reliable measure and correlated in the expected manner with external correlates. These results gain relevance since the need of short measures for measuring personality traits has been increasingly recognized [52], particularly when largescale surveys, to measure multiple constructs, are used. As Luo et al. [15] recommended, the PSCD-SV might be useful in studies where time limited due to other taxing aspects of a research study. For instance, in longitudinal designs where participants have to repeatedly complete large batteries or neuroscience studies where the imaging takes considerable time. The thirteen-item version cuts the time to complete the measure to just over half the time the original version takes to complete by reducing the measure by 10 items. However, where possible and where psychopathy is the chief study variable, we continue to recommend the full 24 -item version of the PSCD. Regardless of the version used, the PSCD appears to a practical tool and it allows for the assessment 
of psychopathic traits in conjunction with $\mathrm{CD}$. This is also signifies that the PSCD may be useful in clinical settings where $\mathrm{CD}$ and personality traits are of relevance to better understand the personality features that may be associated with youth with conduct problems.

Second, the current study may have implications for nomenclature and the DSM-5 [94] and the ICD-11 [95] classification of $\mathrm{CD}$. Notwithstanding the advances and contributions from the CU-based approach, the evidence from this study indicates that the wider construct of psychopathy as well as its component parts could be quite useful for understanding youth with conduct problems. The findings from the current study correspond with other research collected so far across multiple studies conducted in childhood and adolescence which supports the multidimensionality of the psychopathy construct at early developmental stages $[7,11$, $12,15]$. In this regard, the findings from the current study lend further support to the suggestion that all psychopathy dimensions, and not only CU traits, should be included as potential specifiers for $\mathrm{CD}$ in developmental models and diagnostic classification systems [9, 23, 64].

Third, from a theoretical perspective research aimed at disentangling the heterogeneity of conduct problems, with a wider set of psychopathic traits, may help with interventions. This is one of the few studies that examined the contribution of parenting practices in predicting psychopathic traits, taking into account all its dimensions rather than only $\mathrm{CU}$ traits. While this study demonstrates the psychometric properties of the PSCD-SV, it also shows how the PSCD, and measures that consider the broader construct, may have important implications for developmental models aimed at better understanding the mechanisms involved in the development of psychopathy and related behavioral problems, but also for prevention and intervention purposes. Hence, the identification, assessment, and management of those factors able to enhance, maintain, or reduce psychopathy over time should gain more relevance. In this regard, parenting practices should be included in prevention and intervention strategies specifically tailored to the specific needs of children with psychopathic traits. In fact, some promising results from the applied context have shown that focusing on improving parental practices has clinical value not only in reducing problematic behavior in children with high psychopathic traits, but also in favoring a significant reduction in all interpersonal, affective, and behavioral features of psychopathic personality $[28,96]$, although much more work is needed on this topic.

Notwithstanding these contributions, one should bear in mind that these results should be interpreted with caution since the label of psychopathy, as well as psychopathic traits or psychopathic personality, could be pejorative and stigmatizing, particularly when applied at early developmental stages. Yet, when research purposes are prioritized, the study of psychopathic personality in children and adolescents gain relevance since it allows to better understand the development of a disorder with its roots in early childhood [97] and, as was previously mentioned, to improve prevention and intervention strategies that will help to restrain more serious and pervasive patterns of $\mathrm{CD}$ and antisocial behavior [9]. Further research should be conducted on the label in conjunction with $\mathrm{CD}$ as has been done in the past $[98,99]$. Even though a component part (e.g., callous-unemotional traits) have been purported to be less stigmatizing, these terms may also require testing.

\section{Limitations and Future Lines of Research}

This study is not exempt of some limitations that must be taken under consideration. First, relying just on selfreports may have raised the possibility that observed effects were partially due to shared method variance, which means that magnitude and significance of relationships might be overestimated because they were reported by the same informant. Although previous research has indicated the validity and reliability of adolescent selfreports when reporting parenting practices and behavioral problems [100], the use of additional multi-informant approaches is particularly encouraged in future research to confirm relationships and accuracy in estimations. Second, given the nature of the current sample (i.e., community based), the mean levels for psychopathic traits might not be representative of high levels, suggesting the need for replication analyses in high-risk and clinic-referred samples. Third, because psychopathic traits were assessed in the third wave of the study, we were not able to explore test-retest validity, longitudinal stability, and potential interplays between psychopathic traits and parenting practices. Finally, although differences across gender groups could be expected in the observed results, sample size did not allow to accurately examining the results based on gender, a gap that should be particularly filled in future research.

\section{Summary}

The current study examined the PSCD-SV in a sample of adolescents. The PSCD was designed to examine the dimensions of psychopathy in conjunction with $\mathrm{CD}$. Unique to the PSCD is its ability to help clinicians and researchers answer many questions and concerns pertaining to the connections between psychopathy and CD. Other features of the PSCD are the inclusion of an ODD item as well as the focus on daring traits as opposed to impulsivity. These features make the PSCD different from 
other psychopathy scales (e.g., APSD, PCL-YV, YPI, YPI$\mathrm{S})$, making it a potential consideration for researcher and clinicians who are concerned with these various relations or who are interested in an alternate measure of psychopathy. Although additional research is needed, the findings from the current study indicated that this new measure of psychopathy and CD had relatively good psychometric properties, including adequate scale homogeneity and external validity. It suggests that a short version of the measure may well be valuable in research that is aiming to examine psychopathic traits in relation to conduct problems in adolescent samples. This was the first time that the PSCD psychometric properties have been examined in relation to parenting variables, including parental support and psychological control, and simultaneously highlighted how the multicomponent model of psychopathy could be important for investigating the mechanisms (even if partially) that lead to the development of psychopathy. Such investigations are likely to help the field better determine the most appropriate interventions for those children and adolescents with elevated conduct problems and psychopathic traits.

Funding Open Access funding provided thanks to the CRUE-CSIC agreement with Springer Nature. This research was partially funded by Xunta de Galicia under the Programa de Axudas á Etapa Posdoutoral (Consellería de Cultura, Educación e Ordenación Universitaria; 2017, 2019 and 2021) and the Consolidation and structuring of competitive research units and other promotional actions in the universities of the SUG; GRC, 2018

\section{Declarations}

Conflict of interest The authors declare no conflicts of interest.

Open Access This article is licensed under a Creative Commons Attribution 4.0 International License, which permits use, sharing, adaptation, distribution and reproduction in any medium or format, as long as you give appropriate credit to the original author(s) and the source, provide a link to the Creative Commons licence, and indicate if changes were made. The images or other third party material in this article are included in the article's Creative Commons licence, unless indicated otherwise in a credit line to the material. If material is not included in the article's Creative Commons licence and your intended use is not permitted by statutory regulation or exceeds the permitted use, you will need to obtain permission directly from the copyright holder. To view a copy of this licence, visit http://creativecommons.org/licenses/by/4.0/.

\section{References}

1. Hare RD, Neumann CS (2008) Psychopathy as a clinical and empirical construct. Annu Rev Clin Psychol 4:217-246

2. Hare RD (2003) The Hare Psychopathy Checklist-Revised, 2nd edn. Multi-Health Systems, Toronto
3. Harpur TJ, Hare RD, Hakstian AR (1989) Two-factor conceptualization of psychopathy: construct validity and assessment implications. Psychol Assess 1:6-17

4. Cooke DJ, Michie C (2001) Refining the construct of psychopathy: towards a hierarchical model. Psychol Assess 13:171-188

5. Salekin RT, Lynam DR (2010) Handbook of child and adolescent psychopathy. The Guilford Press, New York

6. Salekin RT, Hare RD (2016) Proposed Specifiers for Conduct Disorder (PSCD) Scale. Unpublished test

7. Colins OF, Andershed H, Frogner L, Lopez-Romero L, Veen V, Andershed AK (2014) A new measure to assess psychopathic personality in children: the child problematic traits inventory. J Psychopathol Behav Assess 36:4-21

8. Andershed H (2010) Stability and change of psychopathic traits: what do we know? In: Salekin RT, Lynam DR (eds) Handbook of child and adolescent psychopathy. The Guilford Press, New York, pp 233-250

9. Salekin RT (2017) Research Review: what do we know about psychopathic traits in children? J Child Psychol Psychiatry 58:1180-1200

10. Andershed H, Kerr M, Stattin H, Levander S (2002) Psychopathic traits in non-referred youths: Initial test of a new assessment tool. In: Blaauw E, Sheridan L (eds) Psychopaths: Current international perspectives. Elsevier, Amstersam, pp 131-158

11. Frick PJ, Bodin SD, Barry CT (2000) Psychopathic traits and conduct problems in community and clinic-referred samples of children: further development of the Psychopathy Screening Device. Psychol Assess 12:382-393

12. Lopez-Romero L, Romero E, Colins OF, Andershed H, Hare RD, Salekin RT (2019) Proposed Specifiers for Conduct Disorder (PSCD): preliminary validation of the parent version in a Spanish sample of preschoolers. Psychol Assess 31:1357-1367

13. Zwaanswijk W, Veen VC, Van Geel M, Andershed H, Vedder P (2017) The relation between the bifactor model of the youth psychopathic traits inventory and conduct problems in adolescence: variations across gender, ethnic background, and age. Psychol Assess 29:1065-1070

14. Ellingwood H, Emeno K, Bennell C, Forth A, Kosson D, Hare RD (2017) Multidimensional scaling analysis of psychopathy in male juveniles using the PCL: YV. J Crim Psychol 7:262-279

15. Luo J, Wang MC, Neumann CS, Hare RD, Salekin RT (2021) Factor structure and construct validity of the Proposed Specifiers for Conduct Disorder (PSCD) scale in Chinese adolescents. Assessment 28:1765-1784

16. Salekin RT, Andershed H, Clark AP (2018) Psychopathy in children and adolescents: Assessment and critical questions regarding conceptualization. In: Patrick CJ (ed) Handbook of psychopathy, 2nd edn. The Guilford Press, New York, pp 479-508

17. Andershed H, Colins OF, Salekin RT, Lordos A, Kyranides MN, Fanti KA (2018) Callous-unemotional traits only versus the multidimensional psychopathy construct as predictors of various antisocial outcomes during early adolescence. J Psychopathol Behav Assess 40:16-25

18. Bergstrom H, Farrington DP (2018) Grandiose-manipulative, callous-unemotional, and daring-impulsive: the prediction of psychopathic traits in adolescence and their outcomes in adulthood. J Psychopathol Behav Assess 40:149-158

19. Colins OF, Andershed H, Salekin RT, Fanti KA (2018) Comparing different approaches for subtyping children with conduct problems: callous-unemotional traits only versus the multidimensional psychopathy construct. J Psychopathol Behav Assess 40:6-15

20. Fanti KA, Kyranides MN, Lordos A, Colins OF, Andershed $\mathrm{H}$ (2018) Unique and interactive associations of callous-unemotional traits, impulsivity and grandiosity with child and 
adolescent conduct disorder symptoms. J Psychopathol Behav Assess 40:40-49

21. Frogner L, Gibson CL, Andershed AK, Andershed H (2018) Childhood psychopathic personality and callous-unemotional traits in the prediction of conduct problems. Am J Orthopsychiatry 88:211-225

22. López-Romero L, Colins OF, Fanti K, Salekin RT, Romero E, Andershed H (2020) Testing the predictive and incremental validity of callous-unemotional traits versus the multidimensional construct of psychopathy. J Crim Justice. https://doi.org/ 10.1016/j.jcrimjus.2020.101744

23. Salekin RT (2016) Psychopathy in childhood: Toward better informing the DSM-5 and ICD-11 conduct disorder specifiers. Personal Disord 7:180-191

24. Ribeiro da Silva D, Sousa R, Rijo D, Mendez B, Tsang S, Salekin RT (2021) Proposed Specifiers for Conduct Disorder (PSCD): factor structure and validation of the self-report version in community and forensic samples of Portuguese youth. Assessment. https://doi.org/10.1177/10731911211044534

25. Viding E, Larsson H (2010) Genetics of child and adolescent psychopathy. In: Salekin RT, Lynam DR (eds) Handbook of child and adolescent psychopathy. The Guilford Press, New York, pp 113-134

26. Barker ED, Oliver BR, Viding E, Salekin RT, Maughan B (2011) The impact of prenatal maternal risk, fearless temperament and early parenting on adolescent callous-unemotional traits: a 14-year longitudinal investigation. J Child Psychol Psychiatry 52:878-888

27. Goffin KC, Boldt LJ, Kim S, Kochanska G (2018) A unique path to callous-unemotional traits for children who are temperamentally fearless and unconcerned about transgressions: a longitudinal study of typically developing children from age 2 to 12. J Abnorm Child Psychol 46:769-780

28. McDonald R, Dodson MC, Rosenfield D, Jouriles EN (2011) Effects of a parenting intervention on features of psychopathy in children. J Abnorm Child Psychol 39:1013-1023

29. Cutrín O, Maneiro L, López-Romero L (2020) Parental knowledge and its sources: testing their predictive value for violent and non-violent behaviour in adolescence. In: Roman N (ed) A closer look at parenting practices and styles. Nova Science Publishers, New York, pp 277-299

30. Hoeve M, Dubas JS, Eichelsheim VI, van der Laan PH, Smeenk W, Gerris JRM (2009) The relationship between parenting and delinquency: a meta-analysis. J Abnorm Child Psychol 37:749-775

31. Hoeve M, Stams G, van der Put CE, Dubas JS, van der Laan PH, Gerris JRM (2012) A meta-analysis of attachment to parents and delinquency. J Abnorm Child Psychol 40:771-785

32. Odgers CL, Moffitt TE, Broadbent JM, Dickson N, Hancox RJ, Harrington $\mathrm{H}$ et al (2008) Female and male antisocial trajectories: from childhood origins to adult outcomes. Dev Psychopathol 20:673-716

33. Pinquart M (2017) Associations of parenting dimensions and styles with externalizing problems of children and adolescents: an updated meta-analysis. Dev Psychopathol 53:873-932

34. Hawes DJ, Price MJ, Dadds MR (2014) Callous-unemotional traits and the treatment of conduct problems in childhood and adolescence: a comprehensive review. Clin Child Fam Psychol Rev 17:248-267

35. Waller R, Gardner F, Hyde LW (2013) What are the associations between parenting, callous-unemotional traits, and antisocial behavior in youth? A systematic review of evidence. Clin Psychol Rev 33:593-608

36. Kochanska G, Kim S, Boldt LJ, Yoon JE (2013) Children's callous-unemotional traits moderate links between their positive relationships with parents at preschool age and externalizing behavior problems at early school age. J Child Psychol Psychiatry 54:1251-1260

37. Lopez-Romero L, Romero E, Gomez-Fraguela JA (2015) Delving into callous-unemotional traits in a Spanish sample of adolescents: concurrent correlates and early parenting precursors. J Child Fam Stud 24:1451-1468

38. Waller R, Shaw DS, Forbes EE, Hyde LW (2015) Understanding early contextual and parental risk factors for the development of limited prosocial emotions. J Abnorm Child Psychol 43:1025-1039

39. Hawes DJ, Dadds MR, Frost ADJ, Hasking PA (2011) Do childhood callous-unemotional traits drive change in parenting practices? J Clin Child Adolesc Psychol 40:507-518

40. Pardini DA, Lochman JE, Powell N (2007) The development of callous-unemotional traits and antisocial behavior in children: are there shared and/or unique predictors? J Clin Child Adolesc Psychol 36:319-333

41. Kimonis ER, Bagner DM, Linares D, Blake CA, Rodriguez G (2014) Parent training outcomes among young children with callous-unemotional conduct problems with or at risk for developmental delay. J Child Fam Stud 23:437-448

42. Goulter N, McMahon RJ, Pasalich DS, Dodge KA (2020) Indirect effects of early parenting on adult antisocial outcomes via adolescent conduct disorder symptoms and callous-unemotional traits. J Clin Child Adolesc Psychol 49:930-942

43. Waller R, Gardner F, Hyde LW, Shaw DS, Dishion TJ, Wilson MN (2012) Do harsh and positive parenting predict parent reports of deceitful-callous behavior in early childhood? J Child Psychol Psychiatry 53:946-953

44. Chinchilla MA, Koson DS (2016) Psychopathic traits moderate relationships between parental warmth and adolescent antisocial and other high-risk behaviors. Crim Justice Behav 43:722-738

45. Lynam DR, Loeber R, Stouthamer-Loeber M (2008) The stability of psychopathy from adolescence into adulthood. The search for moderators. Crim Justice Behav 35:228-243

46. Mills-Koonce WR, Willoughby MT, Garrett-Peters P, Wagner N, Vernon-Feagans L, Family Life Project Key Investigators (2016) The interplay among socioeconomic status, household chaos, and parenting in the prediction of child conduct problems and callous-unemotional behaviors. Dev Psychopathol 28:757-771

47. Pasalich DS, Dadds MR, Hawes DJ, Brennan J (2011) Do callous-unemotional traits moderate the relative importance of parental coercion versus warmth in child conduct problems? An observational study. J Child Psychol Psychiatry 52:1308-1315

48. Tilton-Weaver L, Kerr M, Pakalniskeine V, Tokic A, Salihovic S, Stattin H (2010) Open up or close down: how do parental reactions affect youth information management? J Adolesc $33: 333-346$

49. Edens JF, Skopp NA, Cahill MA (2008) Psychopathic features moderate the relationship between harsh and inconsistent parental discipline and adolescent antisocial behavior. J Clin Child Adolesc Psychol 37:472-476

50. Salihovic S, Kerr M, Ozdemir M, Pakalniskiene V (2012) Directions of effects between adolescent psychopathic traits and parental behavior. J Abnorm Child Psychol 40:957-969

51. Backman H, Laajasalo T, Jokela M, Aronen ET (2021) Parental warmth and hostility and the development of psychopathic behaviors: a longitudinal study of young offenders. J Child Fam Stud 30:955-965

52. Romero E, Villar P, Gomez-Fraguela JA, Lopez-Romero L (2012) Measuring personality traits with ultra-short scales: a study of the Ten Item Personality Inventory (TIPI) in a Spanish sample. Pers Individ Dif 53:289-293

53. Oliva A, Parra Á, Sánchez-Queija I, López F (2007) Estilos educativos materno y paterno: evaluación y relación con el ajuste adolescente [Maternal and paternal parenting styles: 
Assessment and relationship with adolescent adjustment]. Anales de Psicología 23:49-56

54. Cutrín O, Maneiro L, Sobral J, Gomez-Fraguela JA (2019) Longitudinal effects of parenting mediated by deviant peers on violent and non-violent antisocial behaviour and substance use in adolescence. Eur J Psychol Appl Legal Context 11:23-32

55. Goodman R, Meltzer H, Bailey V (1998) The Strengths and Difficulties Questionnaire: a pilot study on the validity of the self-report version. Eur Child Adolesc Psychiatry 7:125-130

56. Ortuño-Sierra J, Fonseca-Pedrero E, Paino M, Riba SSI, Muniz J (2015) Screening mental health problems during adolescence: psychometric properties of the Spanish version of the Strengths and Difficulties Questionnaire. J Adolesc 38:49-56

57. Luengo MA, Otero-López JM, Romero E, Gómez-Fraguela JA, Tavares-Filho ET (1999) Análisis de ítems para la evaluación de la conducta antisocial: un estudio transcultural [Item analysis in the assessment of antisocial behavior: a cross-cultural study]. Revista Iberoamericana de Diagnóstico y Evaluación Psicológica 1:21-36

58. Muthén LK, Muthén BO (2011) Mplus user's guide, 7th edn. Muthén \& Muthén, Los Angeles

59. Hu LT, Bentler PM (1999) Cutoff criteria for fit indexes in covariance structure analysis: conventional criteria versus new alternatives. Struct Equ Model 6:1-55

60. McNeish D (2018) Thanks coefficient alpha, we'll take it from here. Psychol Methods 23:412-433

61. Clark LA, Watson D (1995) Constructing validity: basic issues in objective scale development. Psychol Assess 7:309-319

62. Lee SS (2018) Multidimensionality of youth psychopathic traits: validation and future directions. J Psychopathol Behav Assess 40:86-92

63. Lilienfeld SO (2018) The multidimensional nature of psychopathy: five recommendations for research. J Psychopathol Behav Assess 40:79-85

64. Salekin RT (2016) Psychopathy in childhood: why should we care about grandiose manipulative and daring impulsive traits? Br J Psychiatry 209:189-191

65. Forth AE, Book AS (2010) Psychopathic traits in children and adolescents: The relationship with antisocial behaviors and aggression. In: Salekin RT, Lynam DR (eds) Handbook of child and adolescent psychopathy. The Guilford Press, New York, pp 251-283

66. Haas SM, Becker SP, Epstein JN, Frick PJ (2018) Callousunemotional traits are uniquely associated with poorer peer functioning in school-aged children. J Abnorm Child Psychol 46:781-793

67. Marsee MA, Frick PJ, Barry CT, Kimonis ER, Centifanti LCM, Aucoin KJ (2014) Profiles of the forms and functions of selfreported aggression in three adolescent samples. Dev Psychopathol 26:705-720

68. Bubier JL, Drabick DAG (2009) Co-occurring anxiety and disruptive behavior disorders: the roles of anxious symptoms, reactive aggression, and shared risk processes. Clin Psychol Rev 29:658-669

69. Cleckley H (1991) The mask of sanity, 5th edn. Mosby, St. Louis

70. Kimonis ER, Frick PJ, Cauffman E, Goldweber A, Skeem J (2012) Primary and secondary variants of juvenile psychopathy differ in emotional processing. Dev Psychopathol 24:1091-1103

71. Skeem JL, Cooke DJ (2010) Is criminal behavior a central component of psychopathy? Conceptual directions for resolving the debate. Psychol Asses 22:433-445

72. DeLisi M (2009) Psychopathy is the unified theory of crime. Youth Violence Juv Justice 7:256-273
73. Hare RD, Neumann CS (2010) The role of antisociality in the psychopathy construct: comment on Skeem and Cooke. Psychol Assess 22:446-454

74. Hare RD, Neumann CS, Mokros A (2018) The PCL-R assessment of psychopathy: development, properties, debates, and new directions. In: Patrick CJ (ed) Handbook of psychopathy, 2nd edn. The Guilford Press, New York, pp 39-79

75. Miller JD, Lynam DR (2015) Psychopathy and personality: advances and debates. J Pers 83:585-592

76. McMahon RJ, Witkiewitz K, Kotler JS, Conduct Problems Prevention Research Group (2010) Predictive validity of callous-unemotional traits measured in early adolescence with respect to multiple antisocial outcomes. J Abnorm Psychol 119:752-763

77. Lopez-Romero L, Romero E, Luengo MA (2012) Disentangling the role of psychopathic traits and externalizing behaviour in predicting conduct problems from childhood to adolescence. J Youth Adolesc 41:1397-1408

78. Rowe R, Maughan B, Moran P, Ford T, Briskman J, Goodman R (2010) The role of callous and unemotional traits in the diagnosis of conduct disorder. J Child Psychol Psychiatry 51:688-695

79. Frick PJ, Ray JV, Thornton LC, Kahn RE (2014) Can callousunemotional traits enhance the understanding, diagnosis, and treatment of serious conduct problems in children and adolescents? A comprehensive review. Psychol Bull 140:1-57

80. Waller R, Hyde LW (2018) Callous-unemotional behaviors in early childhood: the development of empathy and prosociality gone awry. Curr Opin Psychol 20:11-16

81. Lynam DR, Hoyle RH, Newman JP (2006) The perils of partialling: cautionary tales from aggression and psychopathy. Assessment 13:328-341

82. Beaver KM, Costa CD, Poersch AP, Freddi MC, Stelmach MC, Connolly EJ et al (2014) Psychopathic personality traits and their influence on parenting quality: results from a nationally representative sample of Americans. Psychiatr Q 85:497-511

83. López-Romero L, Romero E, Villar P (2012) Relaciones entre estilos educativos parentales y rasgos psicopáticos en la infancia [Relationships among parenting styles and psychopathic traits in childhood]. Behav Psychol 20:603-623

84. Waller R, Hyde LW (2017) Callous-unemotional behaviors in early childhood: measurement, meaning, and the influence of parenting. Child Dev Perspect 11:120-126

85. Burke JD, Pardini DA, Loeber R (2008) Reciprocal relationships between parenting behavior and disruptive psychopathology from childhood through adolescence. J Abnorm Child Psychol 36:679-692

86. Flom M, White D, Ganiban J, Saudino KJ (2020) Longitudinal links between callous-unemotional behaviors and parenting in early childhood: a genetically informed design. J Am Acad Child Adolesc Psychiatry 59:401-409

87. Tuvblad C, Bezdjian S, Raine A, Baker LA (2013) Psychopathic personality and negative parent-to-child affect: a longitudinal cross-lag twin study. J Crim Justice 41:331-341

88. Waller R, Gardner F, Viding E, Shaw DS, Dishion TJ, Wilson $\mathrm{MN}$ et al (2014) Bidirectional associations between parental warmth, callous unemotional behavior, and behavior problems in high-risk preschoolers. J Abnorm Child Psychol 42:1275-1285

89. Hyde LW, Waller R, Trentacosta CJ, Shaw DS, Neiderhiser JM, Ganiban JM et al (2016) Heritable and nonheritable pathways to early callous-unemotional behaviors. Am J Psychiatry 173:903-910

90. Viding E, Blair RJR, Moffitt TE, Plomin R (2005) Evidence for substantial genetic risk for psychopathy in 7-year-olds. J Child Psychol Psychiatry 46:592-597

91. Waller R, Shaw DS, Hyde LW (2017) Observed fearlessness and positive parenting interact to predict childhood 
callous-unemotional behaviors among low-income boys. J Child Psychol Psychiatry 58:282-291

92. Dotterer HL, Burt SA, Klump KL, Hyde LW (2021) Associations between parental psychopathic traits, parenting, and adolescent callous-unemotional traits. Res Child Adolesc Psychopathol 49:1431-1445

93. Krupić D, Ručević S, Vučković S (2020) From parental personality over parental styles to children psychopathic tendencies. Curr Psychol. https://doi.org/10.1007/s12144-020-00676-6

94. American Psychiatric Association (2013) Diagnostic and statistical manual of mental disorders, 5th edn. American Psychiatric Publishing, Arlington

95. World Health Organization (2019) International classification of diseases for mortality and morbidity statistics, 11 th revision. World Health Organization, Geneva

96. Kimonis ER, Fleming G, Briggs N, Brouwer-French L, Frick PJ, Hawes DJ et al (2019) Parent-child interaction therapy adapted for preschoolers with callous-unemotional traits: an open trial pilot study. J Clin Child Adolesc Psychol 48:S347-S361
97. Raine A (2013) The anatomy of violence: the biological roots of crime. Penguin Books Limited, London

98. Berryessa CM, Wohlstetter B (2019) The psychopathic "label" and effects on punishment outcomes: a meta-analysis. Law Hum Behav 43:9-25

99. Murrie DC, Boccaccini MT, McCoy W, Cornell DG (2007) Diagnostic labeling in juvenile court: how do descriptions of psychopathy and conduct disorder influence judges? J Clin Child Adolesc Psychol 36:228-241

100. Cutrin O, Kulis SS, Ayers SL, Jager J, Marsiglia FF (2021) Perception of parental knowledge by parents and adolescents: unique effects on recent substance use in a Latinx sample. J Lat Psychol 9:189-203

Publisher's Note Springer Nature remains neutral with regard to jurisdictional claims in published maps and institutional affiliations. 